\title{
Post-translational regulation contributes to the loss of LKB1 expression through SIRT1 deacetylase in osteosarcomas
}

\author{
Nadège Presneau ${ }^{1,3}$, Laure Alice Duhamel ${ }^{1}$, Hongtao $\mathrm{Ye}^{2}$, Roberto Tirabosco ${ }^{2}$, Adrienne M Flanagan ${ }^{1,2}$ and \\ Malihe Eskandarpour ${ }^{\star, 1,4}$ \\ ${ }^{1}$ University College London Cancer Institute, 72 Huntley Street, London WC1E 6BT, UK and ${ }^{2}$ Department of Histopathology, Royal \\ National Orthopaedic, Stanmore, Middlesex HA7 4LP, UK
}

\begin{abstract}
Background: The most prevalent form of bone cancer is osteosarcoma (OS), which is associated with poor prognosis in case of metastases formation. Mice harbouring liver kinase B1 (LKB1 ${ }^{+/}$) develop osteoblastoma-like tumours. Therefore, we asked whether loss of LKB1 gene has a role in the pathogenesis of human OS.
\end{abstract}

\begin{abstract}
Methods: Osteosarcomas ( $n=259)$ were screened for LKB1 and sirtuin 1 (SIRT1) protein expression using immunohistochemistry and western blot. Those cases were also screened for LKB1 genetic alterations by next-generation sequencing, Sanger sequencing, restriction fragment length polymorphism and fluorescence in situ hybridisation approaches. We studied LKB1 protein degradation through SIRT1 expression. MicroRNA expression investigations were also conducted to identify the microRNAs involved in the SIRT1/LKB1 pathway.

Results: Forty-one per cent (106 out of 259) OS had lost LKB1 protein expression with no evident genetic anomalies. We obtained evidence that SIRT1 impairs LKB1 protein stability, and that SIRT1 depletion leads to accumulation of LKB1 in OS cell lines resulting in growth arrest. Further investigations revealed the role of miR-204 in the regulation of SIRT1 expression, which impairs LKB1 stability.
\end{abstract}

Conclusions: We demonstrated the involvement of sequential regulation of miR-204/SIRT1/LKB1 in OS cases and showed a mechanism for the loss of expression of LKB1 tumour suppressor in this malignancy.

Osteosarcoma (OS) is the most common non-haematopoietic, primary malignant skeletal neoplasm diagnosed in adolescents and the second leading cause of cancer-related fatalities within this age group. It is the eighth most common form of childhood cancer, representing $2.4 \%$ of all malignancies, and $\sim 20 \%$ of all bone cancers (Ottaviani and Jaffe, 2009). Approximately 150 new cases of OS are diagnosed in the United Kingdom annually, and this incidence is similar to that seen in the western world (WB) (Statistics and outlook for Bone Cancer; www.cancerresearchuk.org). Despite aggressive therapeutic management, which includes neoadjuvant chemotherapy and surgery, $30-40 \%$ of patients die within 5 years of diagnosis (Longhi et al, 2006; Ottaviani and Jaffe, 2009). Several studies have confirmed the complexity and high level of heterogeneity of OS genomes with complex karyotypes (Chen et al, 2014; Kovac et al, 2015; Lorenz et al, 2016). Combined genomic and transcriptomic analysis revealed extensive transcript fusion including PMP22-ELOVL5 gene fusion, recurrent rearrangements in $R B 1, M T A P / C D K N 2 A$

*Correspondence: Dr M Eskandarpour; E-mail: m.eskandarpour@ucl.ac.uk

${ }^{3}$ Current address: Department of Biomedical Sciences, Faculty of Science and Technology, University of Westminster, UK.

${ }^{4}$ Current address: Faculty of Brain Sciences, University College London, London, UK.

Revised 14 May 2017; accepted 22 May 2017; published online 20 June 2017

(C) 2017 Cancer Research UK. All rights reserved 0007 - 0920/17 
and MDM2 genes and also frequent TP53 aberrations (Lorenz et al, 2016). Furthermore, in paediatric OS whole-exome sequencing identified TP53 gene alterations as well as recurrent somatic alterations in the genes $R B 1, A T R X$ and DLG2 in a significant number of tumours (Kovac et al, 2015).

Germline mutations in LKB1 cause Peutz-Jegher Syndrome, a rare disorder predisposing to cancer and multiple gastrointestinal hamartomatous polyps (Sanchez-Cespedes, 2007; Takeda et al, 2007a). Loss of heterozygosity of $L K B 1$ wild-type allele has been reported in $50 \%$ of tumours (gastrointestinal tract, pancreas, cervix, ovary and breast) from patients with germline mutations (Giardiello et al, 1987; Boardman et al, 1998; Ylikorkala et al, 1999; Momcilovic and Shackelford, 2015). Loss of LKB1 has also been reported to induce resistance to TRAIL-mediated apoptosis in OS (Takeda et al, 2007a). Liver kinase B1 loss has also been associated with a more aggressive clinical phenotype in KRAS-mutant nonsmall-cell lung cancer patients accordingly to preclinical models (Calles et al, 2015). In addition, knockdown of endogenous LKB1 gives rise to dysregulation of cell polarity and invasive phenotype of breast cancer cells (Li et al, 2014). Moreover, mice harbouring a heterozygous germline inactivating LKB1 mutation develop gastrointestinal polyps, liver neoplasia and later multifocal osteogenic and osteoblastoma-like tumours (Robinson et al, 2008).

Liver kinase B1 is a serine/threonine kinase, which in humans is encoded by the LKB1/STK11 gene that regulates cell polarity and functions as a tumour suppressor (Baas et al, 2003; Partanen et al, 2012). Liver kinase B1 is an upstream kinase of adenine monophosphate-activated protein kinase (AMPK), a necessary element in cell metabolism that is required for maintaining energy homeostasis. Liver kinase B1 is activated allosterically by binding to the pseudokinase STRAD and the adaptor protein MO25 (Baas et al, 2003; Boudeau et al, 2003; Hawley et al, 2003; Gaude et al, 2011). The LKB1-STRAD-MO25 heterotrimeric complex represents the biologically active unit that is capable of phosphorylating and activating AMPK and at least 12 other kinases that belong to the AMPK-related kinase family as well as other downstream targets such as mTOR, S6K, RPS6 and eIF4E (Hawley et al, 2003; Lizcano et al, 2004; Alexander and Walker, 2011; Hardie and Alessi, 2013; Patel et al, 2014).

It has been shown previously that sirtuin 1 (SIRT1) antagonises LKB1-dependent AMPK activation by promoting the deacetylation, ubiquitination and proteosome-mediated degradation of LKB1 in a senescence model of primary porcine aortic endothelial cells ( $\mathrm{Zu}$ et al, 2010). Sirtuin 1 is a $\mathrm{NAD}^{+}$-dependent deacetylase protein, which has a role in a wide variety of processes including stress resistance, metabolism, differentiation and ageing. Sirtuin 1 binds and regulates the activity of several transcription factors including FOXO1, FOXO3 and FOXO4, HES- 1 and PPAR, NF- $\kappa \mathrm{B}$ and PGC1 (Wang et al, 2011; Hori et al, 2013; Lee and Goldberg, 2013). Sirtuin 1 has been shown to interact with and to deacetylate the p53 tumour suppressor protein (Lain et al, 2008; Yamakuchi et al, 2008).

Although osteoblastoma-like tumours were developed in $L K B 1$ heterozygous mice, screening 113 OS patients found no $L K B 1$ genetic alterations, and in light of those findings, we investigated LKB1 expression in OS cases by hypothesising that SIRT1 deacetylase impairs LKB1 protein and provided further information into the mechanism of expression loss in those tumours.

\section{MATERIALS AND METHODS}

Tumour samples. The tumour samples were obtained from the Stanmore Musculoskeletal Biobank located in the histopathology department of The Royal National Orthopaedic Hospital, and the study was approved by the Cambridgeshire two Research Ethics
Service (reference 09/H0308/165), the UCL Biobank for the Health and Disease ethics committee (covered by the Human Tissue Authority licence 12055; project EC17.1).

Cell culture and transfection. The human OS cell lines SaOS2, HOB, U2OS, MNNG-HOS, HOS, ZK58, KPD, HAL and OSA were obtained from EuroBoNeT (project no. LSHC-CT-2006-018814; http://eurobonet.pathobiology.eu/cd/index.php) and grown in Dulbecco's modified Eagle's medium with $10 \%$ foetal calf serum in $5 \% \mathrm{CO}_{2}$. All cell lines have been authenticated in http:// www.ncbi.nlm.nih.gov/biosample/ and ensured that they are not misidentified. The ZK58, KPD, U2OS, OSA, HAL and OST cell lines were wild type (WT) for TP53, whereas the MNNG-HOS and HOS cell lines carry TP53 mutations, and SaOS2 has a homozygote deletion for TP53 (Ottaviano et al, 2010).

For transient transfections, with morpholinos or mimic microRNAs (miRNA), OS cell lines were transfected in 6-well plates with Endo-Porter (Gene Tools LLC, Philomath, OR, USA), Oligofectamine or Lipofectamine 2000 (Invitrogen, Carlsbad, CA, USA). For permanent knockdown transfection, the MNNG-HOS OS cell line, known to express high level of LKB1 (Takeda et al, 2007b), was manipulated using four hairpin clones of the Open Biosystems (GE Healthcare, Darmacon, Lafayette, CO, USA) pGIPZ human lentiviral shRNAmir-expressing LKB1-targeting shRNA (V3LHS 69003). Cell growth was monitored using a live imaging system, IncuCyte HD (Essen BioScience, Welwyn Garden City, UK). MCF-7 and HEK293T cells, which express little and high levels of LKB1, respectively, at the RNA and protein level, were grown in Dulbecco's modified Eagle's medium supplemented with 10\% FBS. For the knocking-in experiment, a pBABE-LKB1 construction was used (Addgene, Cambridge, MA, USA). The empty backbones were used as a negative control. The vectors were prepared using Maxiprep Kit (Qiagen, Crawley, UK) according to the manufacturer's instructions.

Immunoblotting and immunoprecipitation. Cells were lysed with RIPA lysis buffer (50 mM Tris- $\mathrm{HCl}$ (pH 7.5), $200 \mathrm{mM} \mathrm{NaCl}$ and $10 \mathrm{mM} \mathrm{CaCl}_{2}, 0.5 \% \mathrm{NP} 40$ ) for immunoblotting. The debris was removed by centrifugation and the supernatant was precleared with protein G PLUS beads (Santa Cruz, Dallas, TX, USA), and immunoprecipitated with a rabbit IgG antibody. Precleared lysates were sequentially incubated overnight at $4{ }^{\circ} \mathrm{C}$ (gentle agitation) with the primary antibody $\left(4 \mu \mathrm{g}\left(\mathrm{wv}^{-1}\right)\right.$ for $\left.2 \mathrm{~h}\right)$ and protein $\mathrm{G}$ plus. Immunoprecipitated complexes were resolved by SDS-PAGE ( $8 \%$ acrylamide) for WB analysis. The gels were stained with antiacetyl-lysine antibody, Chip Grade (Abcam, Cambridge, UK). The density of stained proteins was assayed on immunoblots using Image J v1.421 (NIH, Bethesda, MD, USA).

Immunohistochemistry and double immunofluorescence labelling. Immunofluorescent analysis was performed on rehydrated paraffin-embedded full tissue sections $(3-4 \mu \mathrm{m})$. The primary antibodies included anti-SIRT1 $(1: 200$, ab7343), anti-LKB1 (1:100, Ley37D/G6 and ab185734) (Abcam). The conjugated antibodies, anti-mouse Alexa Fluor-488 and anti-rabbit Alexa Fluor-568 (Molecular Probes, Eugene, OR, USA) were used as secondary antibodies. Immunohistochemistry was performed as described previously (Amary et al, 2011). Other antibodies have been listed in Supplementary Table 1.

Cell cycle analysis. Cell cycle analysis was performed using the CyAn ADP flow cytometry (Beckman Coulter, High Wycombe, UK). SaOS2 and HOB cells were seeded in $100 \mathrm{~mm}^{2}$ plates to achieve $60-70 \%$ confluency following $24 \mathrm{~h}$. At 2 days after transfection with morpholino antisense oligos (Gene Tools LLC) blocking SIRT1 RNA, the cells were harvested, centrifuged and washed with PBS. After fixation with ice-cold $70 \% \mathrm{EtOH}$, they were incubated in 7-AAD or anti-BrdU-FITC (BD Pharmingen, 
Oxford, UK). Data were analysed by Summit v4.3 (DakoCytomation, Glostrup, Denmark).

Agilent Human miRNA Microarray V2 and data analysis. Total RNA was extracted (miRNAeasy Kit, Qiagen Ltd, Crawley, UK) and the small RNA fraction was assessed for integrity and quality using Small RNA Kit Lab on Chip (Agilent Technology UK Ltd, Wokingham, UK). One hundred nanogram of total RNA per sample was labelled and hybridised to the Agilent Human miRNA Microarray V2 following the manufacturer's recommendations (Agilent Technology). Microarray slides were scanned using an Agilent Microarray Scanner G2 505B (Agilent Technology) and the images automatically analysed using Feature Extraction Software, version 9.5.1.1 (Agilent Technology). miRNA analysis was carried out using Bioconductor packages for the $\mathrm{R}$ statistical programming language (Gentleman et al, 2004). The (gMedianSignal) background was subtracted (gBGUsed) and the arrays normalised to each other using the 'normexp' function (Ritchie et al, 2007) of the Limma package. The Limma package was also used for differential expression and multiple testing was controlled using the false discovery rate ( $q$-value). The expression patterns were obtained by hierarchical clustering, performed by the Cluster v.3 program and visualised by the TreeView v.1.6 software package http:// bonsai.hgc.jp/ mdehoon/software/cluster/software.htm, and their median presented in a heatmap.

Reverse Transcriptase-quantitative PCR. Complementary DNA was synthesised using the Superscript III First DNA Kit (Invitrogen) and used as a template in SYBR Green PCR Master Mix (Applied Biosystems) to assay LKB1, SIRT1 and SIRT2 mRNA expression. miRNA expressions were investigated using TaqMan miRNA Assay Technology (Applied Biosystems). All reactions were performed in triplicate. The expression of the gene was quantified using either $\Delta \mathrm{Ct}$ or $2^{\wedge}(-\Delta \mathrm{Ct})$ normalised to internal controls, RNU66, GAPDH or 18s (Supplementary Table 2).

LKB1 gene analysis. Twenty-one OS samples from different patients were investigated at the locus of several SNPs along LKB1 gene. The exons 1, 2, 3, 7 and 8 (and the surrounding intron containing the SNPs) were amplified by PCR (Supplementary Table 3) and cleaned using the Qiaquick PCR Purification Kit (Qiagen, Crawley, UK) and analysed by electrophoresis. The status of five SNPs (Supplementary Table 4) was also assessed by restriction digestion (Sobottka et al, 2000).

Fluorescence in situ hybridisation (FISH) was performed using the LKB1 BAC probes generated as described previously (Fernanda Amary et al, 2014). DNA BAC probes were selected from the RP11 library of the Sanger Institute: RP11-81M8 for LKB1 (SpectrumOrange) and RP11-91H11 for the telomeric control (SpectrumGreen) on chromosome 19 (BACPAC Resource Centre, Oakland, CA, USA). Both probes were tested on normal cells' metaphase spread to ensure that they mapped to the right chromosome. To assess the FISH analysis, 50 nuclei were counted in each case and four normal controls were also used to determine the cutoff values for disomy and copy number loss and gain of LKB1.

Statistical analysis. Statistical significance of growth curves was assessed using the Mann-Whitney test using the GraphPad Prism Statistical Software Inc. (GraphPad Software, Inc., La Jolla, CA, USA). $P<0.05$ was considered statistically significant. Average values were expressed as mean \pm s.d.

\section{RESULTS}

LKB1 expression in OSs. Forty-one per cent (106 out of 259) of informative human OS samples from different patients revealed loss of LKB1 expression as assessed by immunohistochemistry (Figure 1A and Supplementary Figure 1). Thirty of these tumours (random selection) were also analysed for LKB1 expression by WB and 14 revealed loss of expression (Figure 1B). The immunohistochemistry and WB data of the primary tumours correlated in 28 of 30 cases (94\%). The absence of immunoreactivity in 6 of 10 cell lines $(60 \%)$ correlated with low or absent detection of LKB1 on WB (Figure 1C).

Loss of LKB1 and activation of mTOR pathway in OS. Using IHC we screened for the expression of key molecules in the mTOR pathway, which could modulate or be modulated by LKB1. The selected molecules studied and their eventual phosphorylation sites were (TSC2 and p-TSC2 (Thr $\left.{ }^{1462}\right)$, mTOR and p-mTOR $\left(\operatorname{Ser}^{2448}\right)$, S6K and p-S6K $\left(\mathrm{Thr}^{389}\right)$, RPS6 and p-RPS6 $\left(\mathrm{Ser}^{235 / 236}\right)$. Representative positive and negative cases by IHC and positive controls are presented in Supplementary Figure 2 and a graphical summary in Figure 1D. We found that LKB1 was not detected in 75 of 133 (56\%) of the OS cases showing mTOR pathway activation, whereas only 16 of 91 (18\%) LKB1-negative cases did not show pathway activation (Figure 1E). Hence, the relative risk of having the pathway activated was 12.78 times higher if LKB1 was absent $(95 \%$ confidence interval). We concluded from the IHC study that the mTOR pathway is activated in a vast majority of OS cases, as shown by the phosphorylation of mTOR, TSC2, S6K or RPS6 in $87 \%$ of our cohort and pathway activation is associated with disease progression (Supplementary Figures 2 and 3).

LKB1 genetic alteration. To investigate further the loss of LKB1 protein expression, we looked for potential genetic alterations in the LKB1 gene. Fluorescence in situ hybridisation of the LKB1 locus gave informative results in 90 OS cases (total 92). Twentyeight of $90(31 \%)$ cases were disomic, and 58 of 90 (65\%) cases showed polysomy (between three and seven copies of chromosome 19 (LKB1 locus 19p13.3)). There was no evidence of copy number loss or gene deletion in the $L K B 1$ locus in any of the 90 cases (Figure 1F). Expression of LKB1 protein assessed by both IHC and WB alongside the FISH results showed that 23 out of $32(72 \%)$ $(P=0.002)$ cases were disomic for $L K B 1$ and lacked LKB1 immunoreactivity (Figure $1 \mathrm{G}$ ). Hence, the loss of LKB1 protein expression in OS is rarely, if ever, explained by the loss of $L K B 1$ gene.

We next investigated whether loss of a parental $L K B 1$ allele could explain the loss of LKB1 protein expression. Twenty-one OS cases, previously studied for protein expression (immunohistochemistry and $\mathrm{WB}$ ) were analysed for the status of 12 SNPs in exons 1,8 and introns 2, 3, 7, 8 (Supplementary Table 4). Of 20 informative cases, eight failed to reveal any DNA variants. Of the remaining 12, parental allelic loss at the rs34928889 locus, accompanied by copy number gain of chromosome 19, was identified in four cases (33.3\% of the 20 cases). Although this finding could explain a copy neutral loss in LKB1 in these cases (Supplementary Tables 3 and 4), direct sequencing of exons 1, 4, 5, 6 and 8 of the 20 informative cases failed to detect any genetic alterations. In addition, no mutations were found in exons 2, 3 and 7 in the four cases presenting loss of a parental allele. Furthermore, whole-genome sequencing with the Illumina HiSeq Platform (performed at Sanger Institute as part of an on-going collaboration), on 113 OS cases also showed no significant LKB1 genetic alterations (data no shown).

LKB1 expression at the transcriptional level. To test whether loss of $L K B 1$ mRNA level could account for the loss of protein expression, $L K B 1$ mRNA levels in human OS samples and cell lines were correlated with their protein levels. The RT-qPCR for $L K B 1$ mRNA level was performed on 11 OS cell lines and 23 OS cases. All the OS cases expressed detectable and significant LKB1 mRNA levels compared with the average RNA level of the positive controls (Jurkat, HF1 cell lines) (Figure 1I), regardless of LKB1 protein expression levels, analysed by WB and IHC (Figure 1I). 
A

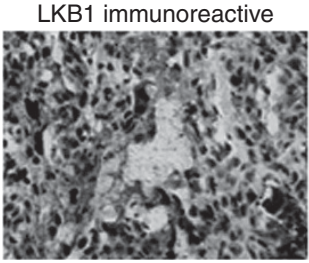

LK1 non-immunoreactive

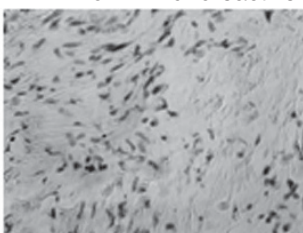

Scoring

F

\begin{tabular}{|l|c|}
\hline Polyomy & $61 / 92(66 \%)$ \\
\hline Copy number gain of LKB1 & $14 / 92(15 \%)$ \\
\hline $\begin{array}{l}\text { Copy number gain of telomere/ } \\
\text { copy neutral loss of LKB1 }\end{array}$ & $2 / 92(2 \%)$ \\
\hline $\begin{array}{l}\text { Loss of hetrozygosity or gene } \\
\text { deletion }\end{array}$ & $0 / 92(0 \%)$ \\
\hline Disomy & $28 / 92(30 \%)$ \\
\hline
\end{tabular}
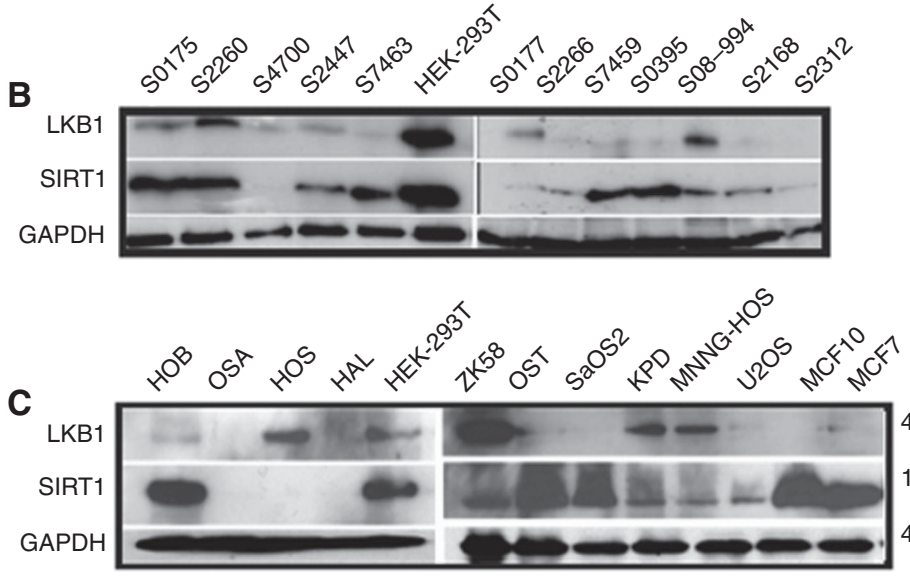
$49 \mathrm{kDa}$
$110 \mathrm{kDa}$
$48 \mathrm{kDa}$

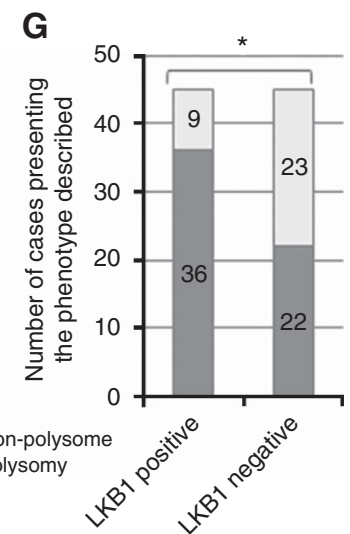

D

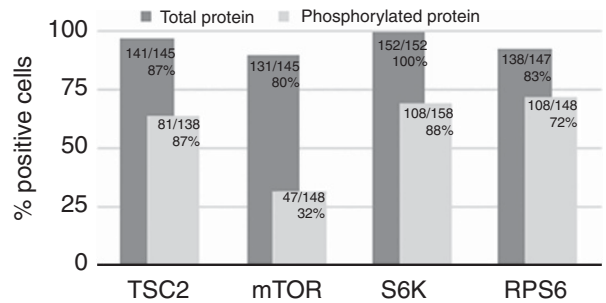

$\mathbf{E}$
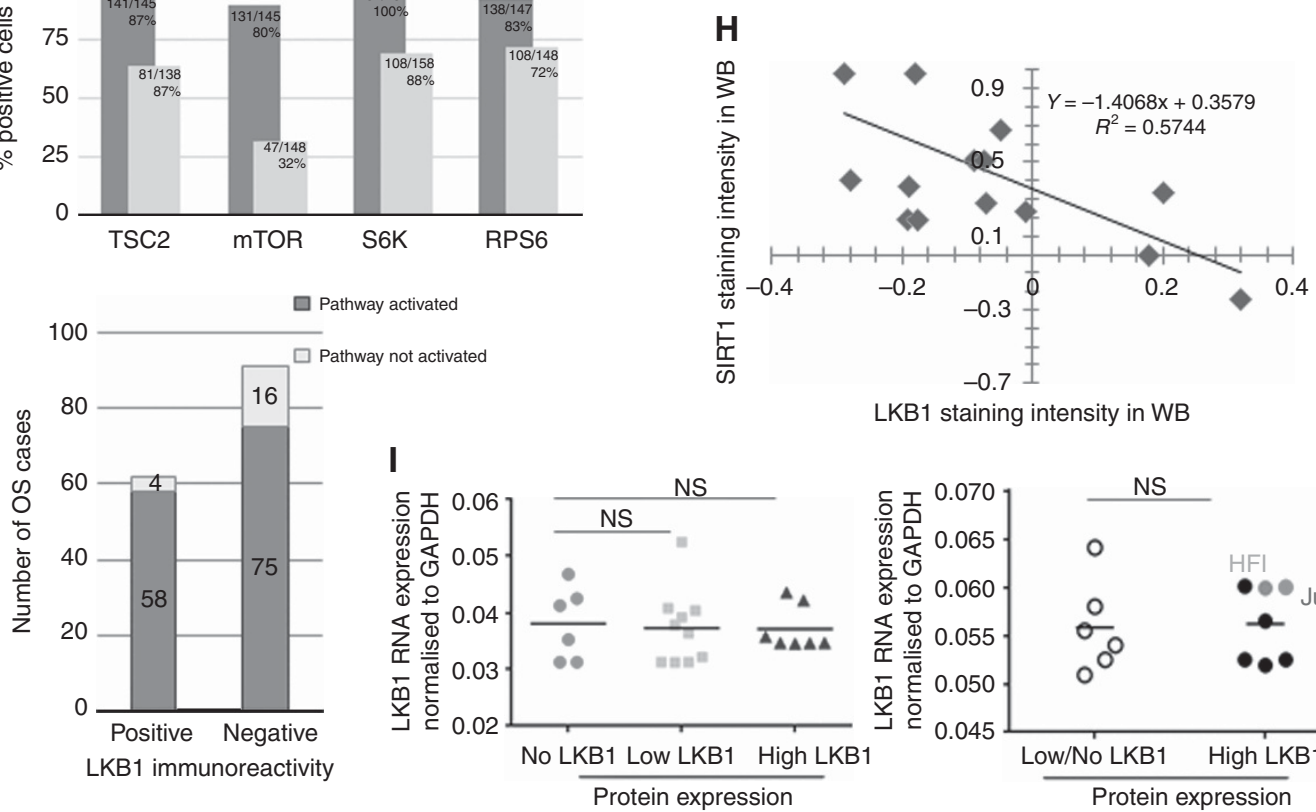

LKB1 staining intensity in WB

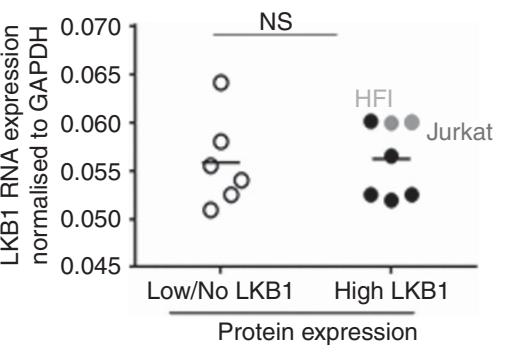

Figure 1. LKB1 expression and its genetic alterations in osteosarcomas. (A) IHC of LKB1 in two OS with positive immunoreactivity (left) and negative immunoreactivity (right). (B) Immunoblots of endogenous LKB1 and SIRT1 protein expression in OS tumours ( $n=12$ cases) normalised to glyceraldehyde 3-phosphate dehydrogenase (GAPDH) expression. HEK293T cells was used as a positive control. (C) Immunoblots on OS cell lines using anti-LKB1 and SIRT1. Control cell lines HEK-293T (positive for LKB1 expression) and MCF7 and MDA-MB (negative for LKB1) were compared for LKB1 immunoreactivity in OS cell lines and patient biopsies. (D) Expression of phosphorylated and total protein for mTOR, S6K and RPS6.

(E) Association between LKB1 and mTOR pathway activation in OS. Bar chart representing the LKB1 immunoreactivity compared with the pathway activation, for $P<5 \times 10^{-15}$ with Wilcoxon's signed-rank test. (F) FISH for LKB1 locus on tissue microarray (TMA) samples. Copy number loss of $L K B 1$ was defined by a ratio of $L K B 1$ over telomere strictly $<1$ in at least $20 \%$ of the cells and copy number gain by a ratio strictly over 1 in at least $10 \%$ of the cells. The FISH data has been summarised in a graph. (G) Bar chart represents the correlation between occurrence of chromosome 19 polysomy and the expression of LKB1 protein in OS patients. ${ }^{*} P<0.005$ with the one-tailed Fisher's exact test. (H) Pearson's correlation between LKB1 and SIRT1 staining intensity in OS immunoblots of 12 samples. The immunoblots were scanned and analysed by Image $J$ and data were plotted to see the relationship. The expression levels were normalised to the GAPDH and compared with the HEK293T WB bands as a positive control $(r=-0.086$, $P<0.01$ ). (I) RT-qPCR on OS cases with no, low and high protein expression of LKB1 (left graph), also on OS cell lines with no/low and high LKB1 protein expression (right graph). $2^{\wedge}(-C T)$ indicating $L K B 1$ mRNA expression normalised to GAPDH expression, unpaired $t$-test between the groups, $P>0.05, \mathrm{NS}=$ no significant. A full colour version of this figure is available at the British Journal of Cancer journal online. 

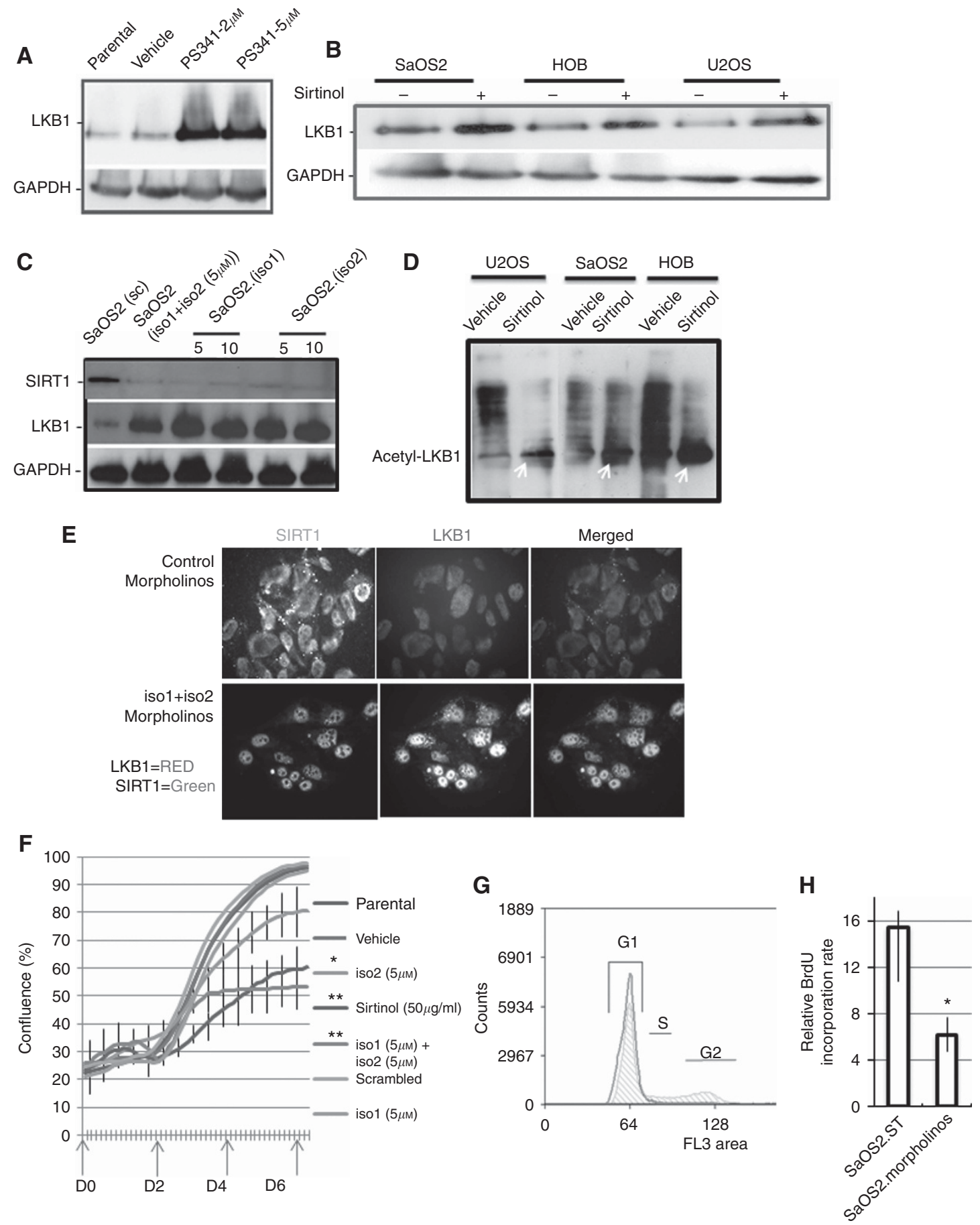

Figure 2. LKB1 regulation via protein degradation machinery. (A) WB for LKB1 on SaOS2 cells exposed for $8 \mathrm{~h}$ with PS-341 (2 or $5 \mu \mathrm{M})$ or vehicle, (B) SaOS2, HOB and U2OS cells were treated $(+)$ or not $(-)$ with sirtinol $\left(50 \mu \mathrm{g} \mathrm{ml}^{-1}\right)$ for $24 \mathrm{~h}$ and then lysates were immunoblotted for LKB1 and glyceraldehyde 3-phosphate dehydrogenase (GAPDH). (C) The SaOS2 cells were transfected with morpholinos targeting SIRT1 isoforms (5 and $10 \mu \mathrm{M})$ or both ( $5 \mu \mathrm{M}$ of each) and then blotted for SIRT1 and LKB1 proteins. (D) HOB, SaOS2 and U2OS cell lines were treated either with sirtinol $\left(50 \mu \mathrm{g} \mathrm{ml}^{-1}\right)$ or vehicle control for $24 \mathrm{~h}$. LKB1 was immunoprecipitated (IP) from protein lysates using protein G and the level of acetylated LKB1 were determined using anti-acetyl-lysine in WBs and indicated by arrows. (E) The SaOS2 cell lines were transfected with morpholinos (iso1 $(5 \mathrm{nM})+$ iso2 $(5 \mathrm{nM})$ or scrambled and stained for LKB1 and SIRT1 for immunofluorescence microscopy. (F) The SaOS2 cells treated either with sirtinol $\left(50 \mathrm{~g} \mathrm{ml}^{-1}\right)$ or transfected with morpholinos (iso1 $(5 \mathrm{~nm})+$ iso2 $(5 \mathrm{~nm})$ ) revealed a growth arrest monitored by live cell imaging system. Statistical significance was accepted at ${ }^{*} P$-value $<0.05$ and $* P<0.01$. (G) Cell cycle profile for SaOS2 cells, 2 days post-transfection with morpholinos, using incorporation of propidium iodide (PI) or bromodeoxyuridine (BrdU). Representative flow cytometric data showing the cell cycle distribution and growth arrest in the G1 phase in SIRT1-suppressed cells. $(\mathbf{H})$ The percentage of BrdU-positive cells was determined by microscopic observation. BrdU-positive and -negative cells were counted at $\times 200$ magnification and at least 200 cells were counted in each slide. The graph shows the average number of cells from each field (at least $n=10$ ) counted in three independent experiments; the bars represent the mean. ${ }^{*}$-value $<0.05$. A full colour version of this figure is available at the British Journal of Cancer journal online. 

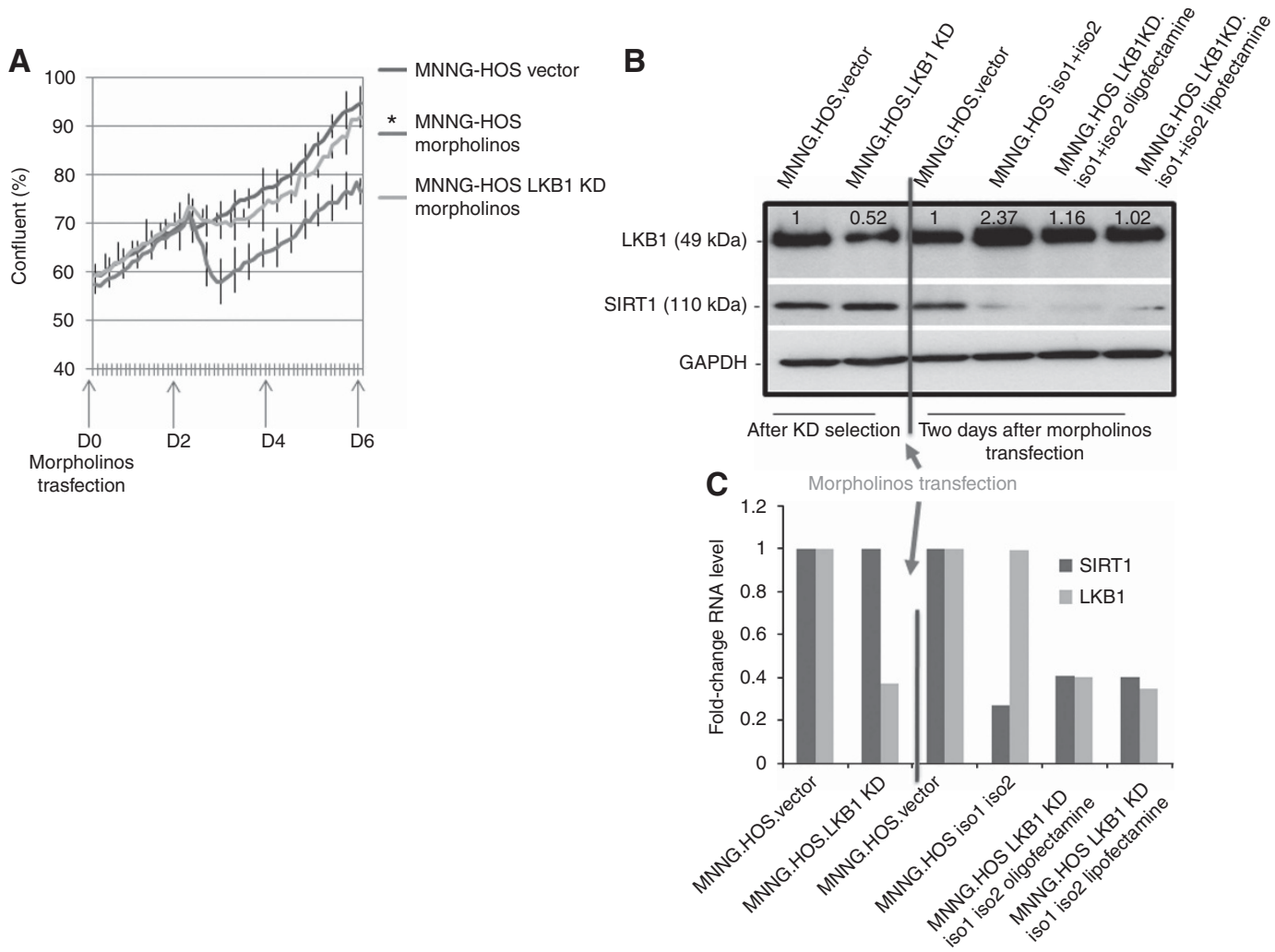

Figure 3. SIRT1 suppression and growth arrest modulation by LKB1. (A) Using lentivirus-expressing LKB1-targeting short hairin RNA (shRNA), LKB1 was stably knocked down (KD) ( 50\%) in MNNG-HOS cells. One day after selection by puromycin (10 $\left.\mu \mathrm{g} \mathrm{ml}{ }^{-1}\right), \mathrm{MNNG}^{-\mathrm{HOS}}$ KD LKB1 cells were transfected with morpholinos (iso1 + iso2 $(5 \mathrm{~nm})$ ) and their growth was monitored using live imaging system ( $\left.{ }^{*} P<0.05\right)$. (B and $\left.\mathbf{C}\right)$ The MNNG-HOS KD LKB1 cells, transfected with morpholinos or control vector, were lysed 2 days after transfection with morpholinos, and immunoblotted using antibodies anti-LKB1, SIRT1 or glyceraldehyde 3-phosphate dehydrogenase (GAPDH). RT-qPCR on LKB1 and SIRT1 mRNA expression was also performed on the cells treated in the same conditions. A full colour version of this figure is available at the British Journal of Cancer journal online.

LKB1 tumourigenicity in OS. We studied the role of LKB1 in tumourigenicity by functional approaches. OST, SaOS2 and OSA cell lines, which express very low levels of the endogenous LKB1 protein, were transfected with pBABE-LKB1 (LKB1-(knock-in) KI) or empty vector (ET-KI) as control and then studied for Anoikis, cell survival and proliferation. Although there was no significant difference in cell cycle profile, consistent reduced growth rate and increased apoptosis in non-adherent condition was observed in LKB1-KI cells compared with ET-KI (Supplementary Figure 5). MTS assay on SaOS2 LKB1-KI cells also showed a decreased metabolism compared with the ET-KI at different cell densities, and were statistically significant at days 2 and 3 in the lowest cell density ( $P=0.0099$ and $P=0.023$, respectively) and the intermediate cell density ( $P=0.0034$ and $P=0.030$, respectively). Loss of LKB1 function was investigated in MNNG-HOS cells known to express LKB1 at the high level at both mRNA and protein levels. Cell-based assays on knockdown cells revealed that LKB1-KD cells gained a growth rate compared with the pGTC-(empty vector) ET with no difference in cell cycle profile (Figure 3A).

Inverse correlation of LKB1 and SIRT1 expression in OS. We next tested whether the loss of LKB1 expression in OS could be brought about through the protein degradation machinery, and specifically through SIRT1 function. Figures $1 \mathrm{~B}, \mathrm{C}$ and $\mathrm{H}$ show the inverse correlation of LKB1 and SIRT1 expression in OS patients and OS cell lines. Samples expressing high level of SIRT1 expressed low amount of LKB1 and, inversely, samples with high LKB1 expression showed a low level of SIRT1 expression $y=-1.4068$ $x+0.3579, R^{2}=0.5744$ (Figure $1 \mathrm{H}$ ). The inverse correlation was also supported by double-immunofluorescence labelling using antibodies targeting LKB1 and SIRT1 (Figures 4C and D). However, no inverse correlation was found at mRNA levels of SIRT1 and LKB1 in those tumours. Furthermore, in tumours and OS cell lines with low or high level of LKB1 protein expression, there was no significant difference in RNA levels (Figure 1I).

SIRT1 regulates $\mathrm{LKB} 1$ protein expression. Treatment of SaOS2 cell line with a proteasome inhibitor, PS-341 (MG-341), resulted in LKB1 protein accumulation, the degradation of which was protected by the molecule PS-341 (Figure 2A). This was reversed by treatment with sirtinol, an SIRT1 deacetylase inhibitor, and morpholino antisense oligonucleotides (Figures $2 \mathrm{~B}$ and $\mathrm{C}$ and Supplementary Table 5), which was specific for SIRT1 and not SIRT2 (Supplementary Figure 4). Treatment of the OS cell lines SaOS2, HOB and U2OS with sirtinol and immunoprecipitation with the anti-LKB1 antibody SIRT1 exerted a significant effect on LKB1 acetylation (Figure 2D). Sirtuin 1/LKB1 cell localisations were studied in SaOS2 (Figure 2E) and HOB cells (data not shown) post-transfection with morpholinos and control. In addition, inactivation/suppression of SIRT1 in SaOS2 cells resulted in growth arrest in the G1 phase because of SIRT1 reduction and LKB1 accumulation in those cells (Figures 2E-H).

The MNNG-HOS cells were transfected stably with lentivirus to knockdown LKB1 expression and cell growth was monitored (Figure 3A). Subsequently, the knocked down LKB1 cells were treated with morpholinos to suppress SIRT1 expression and the levels of LKB1 and SIRT1 expression (RNA and protein) were analysed and compared with the controls (Figures $3 \mathrm{~B}$ and $\mathrm{C}$ ). A significant accumulation of LKB1 protein (100\%) (Figure 3B) was observed in the absence of SIRT1 expression in the MNNG-HOS 

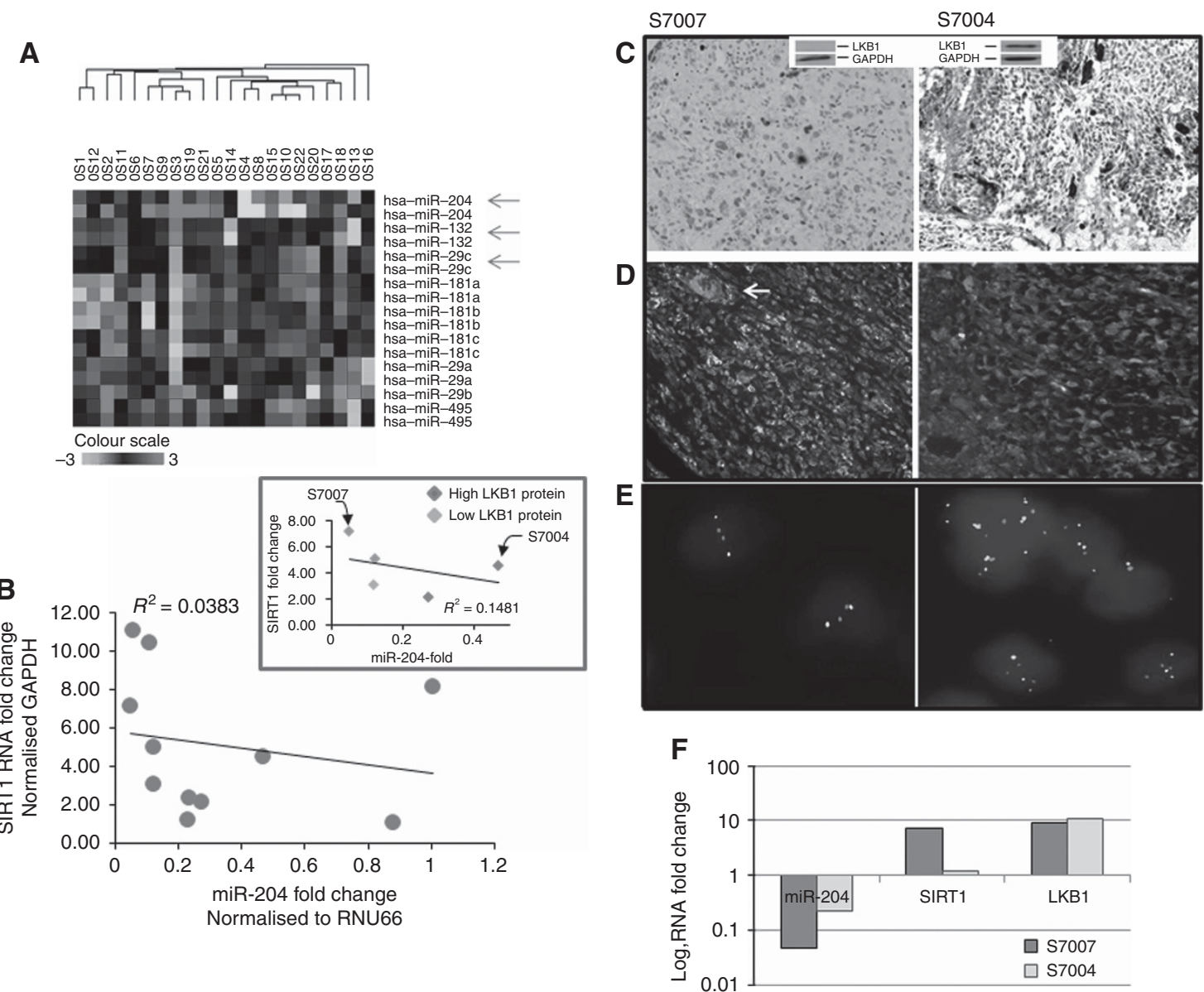

Figure 4. miR-204/SIRT1/LKB1 regulation in OS. (A) Supervised hierarchical clustering analysis based on the predicted miRNAs targeting SIRT1 in 22 OS showed significant differentially expressed miRNAs (miR-204, miR-29c and miR-132) with a $P<0.05$ between OS cases. Expression levels are displayed in a colour spectrum that extends from light green (low expression) to bright red (high expression). (B) miR-204 RT-qPCR on OS tumours compared with SIRT1 mRNA level expression was normalised to RNU66 and glyceraldehyde 3-phosphate dehydrogenase (GAPDH), respectively. $P$-value $<0.01 . Y=-2.1389 X+5.7927, R^{2}=0.0383$. In those samples, the level of LKB1 protein expression was compared between the informative cases (inset graph). $R^{2}=0.1481$ (regression values) $(P<0.05)$. (C) Two representative OS cases have been shown here, for low (S7007) and high (S7004) levels of LKB1 protein expression. The WB inset also confirmed the level of LKB1 expression in agreement with IHC. (D) Double IF staining for LKB1 and SIRT1 on same two tumours. Red cells indicate LKB1 and green cells indicate SIRT1 expression. Osteoclasts with a high level of LKB1 have been marked by arrows. Stromal cells expressing both LKB1 and SIRT1 resulted in a yellow colour from the merge colours (colocation). (E) Tumours were analysed by interphase FISH. S7007 was indicated as polysomic with the presence of at least three copies per cell of both LKB1 and the telomere in over $10 \%$ of the cells. Tumour S7004 was indicated as disomic. (F) RT-qPCR relative expression for miR-204, SIRT1 and LKB1 mRNAs normalised to RNU66 and GAPDH, respectively. A full colour version of this figure is available at the British Journal of Cancer journal online.

cells, while the LKB1 knockdown MNNG-HOS cells lost their potential to accumulate LKB1 protein.

miR-204 regulates SIRT1 expression in OS. We analysed the 22 OS cases, characterised for SIRT1 and LKB1 status, for miRNA expression using Agilent miRNA array in a supervised manner for SIRT1 target miRNA genes acquired from miRWalk2.0 algorithms (http://www.umm.uni-heidelberg.de/apps/zmf/mirwalk/) (Supplementary Table 6). The expression patterns were obtained and their median presented in a heatmap (Figure 4A). miR-29c, miR-132 and miR-204, which target SIRT1, were among the microRNAs differentially and significantly expressed between OS cases (Figure 4A and Supplementary Table 7). However, RT-qPCR, for those miRNAs, on OS cases revealed that $72 \%$ (14 out of 18) of OS had relative low expression of miR-204 normalised to RNU66 level. From those samples $(n=14), 11$ informative cases, 67\% (11 out of 14), showed a high level of SIRT1 mRNA expression. In addition, we found a significant correlation $\left(R^{2}=0.0383\right)$ between the low expression of miR-204 and high SIRT1 expression (Figure 4B). This finding was in a reverse correlation with LKB1 levels (low level of LKB1) in informative cases (inset in Figure $4 \mathrm{~B}$, $P<0.05)$.

miR-204/SIRT1/LKB1 sequential pathway. Double immunofluorescence staining and WB on informative OS cases showed that the expression of SIRT1 and LKB1 in protein level had a reverse correlation. Two cases were selected based on the low (S7007) and high (S7004) levels of LKB1 expression in IHC and WB (Figures $4 \mathrm{C}$ and D). Fluorescence in situ hybridisation analysis confirmed trisomy at LKB1 locus in sample S7004 (Figure 4E), while there was no significant difference in the level of RNA expression between the two cases. Although in both samples, LKB1 mRNA was found to be expressed at the same level, while SIRT1 mRNA in S7004 was lower than S7007, and this coincided with a higher expression level of miR-204 in S7004 compared with that in S7007 (Figure 4F).

As miR-204 appeared to be the most relevant microRNA in this setting, compared with the data obtained from miR-132 and miR$29 \mathrm{c}$ experiments, we studied the effect of miR-204 in SaOS2 cell line found to express a low level of miR-204. The cells were 
A
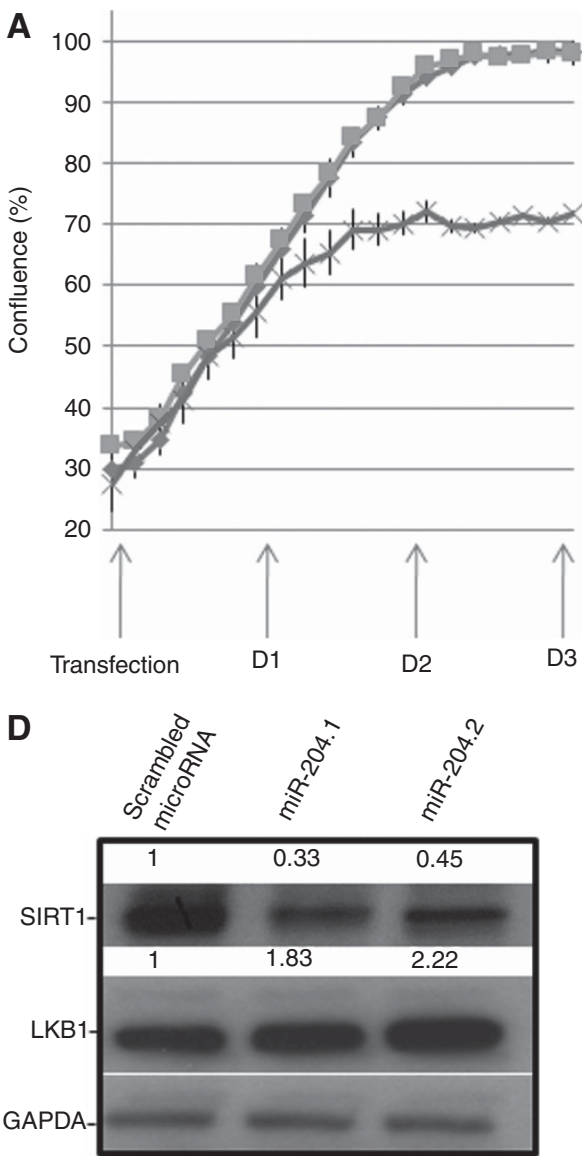

B
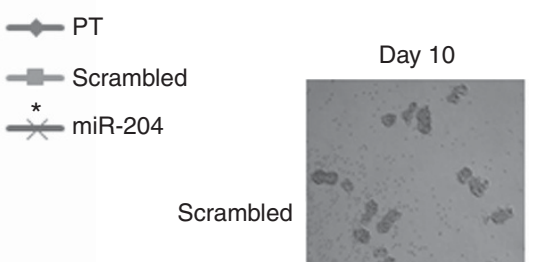

miR-204
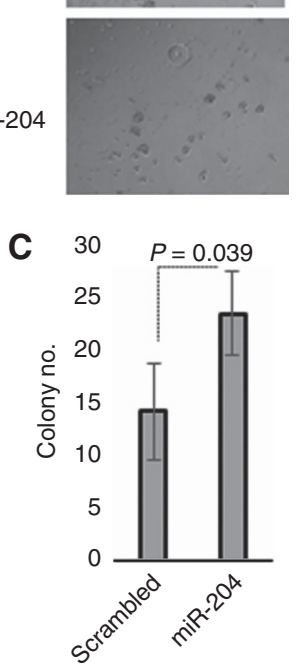

Figure 5. miR-204 regulates SIRT1/LKB1 pathway. (A and B) Cell growth and colony formation of SaOS2 cells after transfection with mimic miR-204 $(100 \mathrm{~nm})$ in duplicate samples. ( $\left.{ }^{\star} P<0.05\right)$. (C) The graph shows the average number of colonies (at least 10 cells) from each field (at least $\left.n=5\right)$ counted in two independent experiments; the bars represent the mean. (D) WB for SIRT1 and LKB1 on SaOS2 cells after exposure to miR-204 mimic; protein levels as indicated by densitometry. A full colour version of this figure is available at the British Journal of Cancer journal online.

transfected with mimics of miR-204 and subsequently cell growth and anchorage-independent growth/colony formation was assessed (Figures 5A-C). Sirtuin 1 and LKB1 protein expressions were also analysed and showed almost $50 \%$ reduction in SIRT1 protein levels and double expression of LKB1 in the cells transfected with miR204 compared with the scrambled miRNA on day 4 of posttransfection (Figure 5D).

\section{DISCUSSION}

The role of LKB1 in cancer has recently stimulated considerable interest. Although it has been shown that the somatic inactivation of $L K B 1$ is associated with the development of cancer in several tissues (Zhong et al, 2006; Ji et al, 2007; Shorning and Clarke, 2011), the role of LKB1 in OS has not been studied in depth. In this study, we report the absence of LKB1 expression in $41 \%$ of OS, which was not due to any genetic alterations as previously shown in concordance with Lorenz et al (2016) and the COSMIC database, http://www.sanger.ac.uk/genetics/CGP/cosmic/). Analysing LKB1 at the mRNA level and performing miRNA array did not support the idea of deficiency at the transcriptional level, in spite of reports showing miRNAs, miR-451 and miR-155, targeting LKB1 mRNA in glioma cells and cervical cancer cells, respectively (Godlewski et al, 2010; Lao et al, 2014). The absence of LKB1 protein expression in spite of the presence of mRNA implies a post-translational mechanism. Sirtuin 1 deacetylase have important roles in many biological pathways, including cancer development
(Sanchez-Cespedes et al, 2002; Ji et al, 2007; Lim, 2007; Deng, 2009; Wingo et al, 2009; Knight and Milner, 2012). Sirtuin 1 can modulate cell survival by regulating the transcriptional activities of p53, NF- $\kappa$ B (Yeung et al, 2004), FOXO proteins (Wang et al, 2011) and p300 (Bouras et al, 2005; Li and Luo, 2011). It has been shown that SIRT1 inhibition decreases Foxp3 polyubiquitination, thereby increasing the Foxp3 protein level (van Loosdregt et al, 2011). Furthermore, our group recently reported that high SIRT1 protein expression was associated with metastases in Ewing sarcoma and a poor prognosis (Ban et al, 2014), showing the important role of this molecule in bone tumours. In addition, here we showed that loss of LKB1 could induce constitutive mTOR activation, even in the absence of detection of p-TSC2 $\left(\mathrm{Thr}^{1462}\right)$, and in vitro gain of LKB1 in OS cell lines shows a tumourigenic function.

We provide evidence via the use of small compound inhibitors and gene suppression that LKB1 loss is through post-translational regulation. We found that LKB1 deacetylase by SIRT1 facilitates LKB1 proteasomal degradation. A mutually exclusive/reverse expression of SIRT1 and LKB1 protein shown by WB and double immunofluorescence microscopy also support this finding. Therefore, it appears that SIRT1 impairs LKB1 protein stability and that SIRT1 depletion leads to the accumulation of LKB1 in OS cell lines resulting in growth arrest. In LKB1 knockdown OS cells, LKB1 is restored by SIRT1 inhibitor or morpholinos, resulting in increased proliferation. These findings reveal a possible mechanism for the loss of expression of LKB1 tumour suppressor in OS. This is in agreement with $\mathrm{Zu}$ et al (2010), who showed that SIRT1 antagonises LKB1-dependent AMPK activation by promoting the deacetylation, ubiquitination and proteosome-mediated 
degradation of LKB1, in a senescence model in primary porcine aortic endothelial cells ( $\mathrm{Zu}$ et al, 2010). Recently, it has been reported that SIRT1 expression prevents adverse arterial remodelling by facilitating HECT and RLD domain-containing E3 ubiquitin protein ligase 2-mediated degradation of acetylated LKB1 and acetylation at K64, LKB1 showed an enhanced interaction with SIRT1 (Bai et al, 2016). However, Lan et al, 2008 demonstrated that overexpression of SIRT1 in $293 \mathrm{~T}$ cells diminished acetylation of LKB1 and caused its movement from the nucleus to the cytoplasm, where LKB1 can associate with the adaptor proteins, STE20-related adaptor protein and mouse embryo scaffold protein, resulting in its own activation and subsequent activation of AMPK pathway (Lan et al, 2008). We showed here that immunofluorescence colocalisation of LKB1 and SIRT1 on OS cell lines (SaOS2, HOB, U2OS), treated with sirtinol or morpholinos, led to the accumulation of LKB1 in the cytoplasm. We showed that LKB1 was predominantly localised in the cytoplasm after SIRT1 inhibition. In addition, STRAD always colocalised with LKB1 in the cytoplasm (data not shown). Consistent with our results of reverse correlation of SIRT1 and LKB1 function, it has been shown that metformin, a SIRT1 activator and widely used as an antidiabetes drug, can suppress memory of hyperglycaemia stress and ROS generation in the retinas of diabetic animals through the SIRT1/LKB1/AMPK/ROS pathway (Zheng et al, 2012).

Investigating SIRT1 upstream regulators demonstrated the posttranscriptional regulation of SIRT1 by miRNAs and RNA-binding proteins. More than 16 miRNAs have been found in silico and experimentally to regulate both SIRT1 expression and activity (Yamakuchi, 2012). Among them are miR-29c, miR-132 and miR204, which have been shown to contribute to tumour progression by downregulating the expression of SIRT1 ( Strum et al, 2009; Saunders et al, 2010; Zhang et al, 2013; Bae et al, 2014). Performing mimic studies on miR-204 showed a growth arrest in SaOS2 cells, which coincided with SIRT1 protein reduction and an accumulation in LKB1 protein expression. These data are in agreement with Shi et al (2015), showing that miR-204 inhibits proliferation and epithelial-mesenchymal transition via SIRT1 (Zhang et al, 2013) in gastric cancer cells. However, miR-204 has other target genes, which also lead to cell growth arrest (Shi et al, 2014; Yin et al, 2014; Sun et al, 2015; Wu et al, 2015). All these findings suggest a sequential regulation between those molecules. Therefore, the low expression of these miRNAs may contribute to tumour development in the context of SIRT1 upregulation and LKB1 downregulation in a subset of OS cases.

Despite developing osteoblastic tumours in $L K B 1^{+/-}$mice (Robinson et al, 2008), we could not find any genetic alterations at the LKB1 locus in OS, even though OS revealed loss of LKB1 protein expression. Furthermore, we showed that SIRT1 upregulation in OS has a significant correlation with LKB1 loss, and that SIRT1 suppression revealed a restoration and accumulation of LKB1 and growth arrest. We also demonstrated a role for miR-204 in the SIRT1/LKB1 pathway, which may explain the loss of LKB1 expression through SIRT1 expression and its potential in arresting growth and attenuation of anchorage-independent growth in OS cells. Our findings suggest involvement of sequential regulation of miR-204-SIRT1-LKB1 in OS development. Therefore, targeting this pathway may represent a useful therapeutic approach to control OS growth in those subsets demonstrating loss of LKB1 expression.

\section{ACKNOWLEDGEMENTS}

We are grateful to the individuals who participated in the research project and to the clinicians, and support staff in the London Sarcoma Service involved in their care. We are also grateful to
Professor Chris Boshoffs lab for providing synthetic miR-132 to do the mimic studies, Dr Stephen Henderson for analysing the miRNA microarray data and UCL Cancer Institute sequencing facility. The research was funded by Skeletal Cancer Action Trust (SCAT) UK. The work could not have been carried out without the existence of the Stanmore Biobank, a satellite of the UCL Biobank for Health and Disease, which is supported by the Research and Development Department of the Royal National Orthopaedic Hospital.

\section{CONFLICT OF INTEREST}

The authors declare no conflict of interest.

\section{AUTHOR CONTRIBUTIONS}

AMF initiated and supervised the project; ME conducted the experiments, analysed the data and wrote the manuscript; LD performed genetic screening, some IHC and FISH; NP conducted genetic screening and helping with writing the manuscript; HY performed FISH analysis; RT provided clinicopathological expertise.

\section{REFERENCES}

Alexander A, Walker CL (2011) The role of LKB1 and AMPK in cellular responses to stress and damage. FEBS Lett 585(7): 952-957.

Amary MF, Bacsi K, Maggiani F, Damato S, Halai D, Berisha F, Pollock R, O’Donnell P, Grigoriadis A, Diss T, Eskandarpour M, Presneau N, Hogendoorn PC, Futreal A, Tirabosco R, Flanagan AM (2011) IDH1 and IDH2 mutations are frequent events in central chondrosarcoma and central and periosteal chondromas but not in other mesenchymal tumours. J Pathol 224(3): 334-343.

Baas AF, Boudeau J, Sapkota GP, Smit L, Medema R, Morrice NA, Alessi DR, Clevers HC (2003) Activation of the tumour suppressor kinase LKB1 by the STE20-like pseudokinase STRAD. EMBO J 22(12): 3062-3072.

Bae HJ, Noh JH, Kim JK, Eun JW, Jung KH, Kim MG, Chang YG, Shen Q, Kim SJ, Park WS, Lee JY, Nam SW (2014) MicroRNA-29c functions as a tumor suppressor by direct targeting oncogenic SIRT1 in hepatocellular carcinoma. Oncogene 33(20): 2557-2567.

Bai B, Man AW, Yang K, Guo Y, Xu C, Tse HF, Han W, Bloksgaard M, De Mey JG, Vanhoutte PM, Xu A, Wang Y (2016) Endothelial SIRT1 prevents adverse arterial remodeling by facilitating HERC2-mediated degradation of acetylated LKB1. Oncotarget 7(26): 39065-39081.

Ban J, Aryee DN, Fourtouna A, van der Ent W, Kauer M, Niedan S, Machado I, Rodriguez-Galindo C, Tirado OM, Schwentner R, Picci P, Flanagan AM, Berg V, Strauss SJ, Scotlandi K, Lawlor ER, Snaar-Jagalska E, Llombart-Bosch A, Kovar H (2014) Suppression of deacetylase SIRT1 mediates tumor-suppressive NOTCH response and offers a novel treatment option in metastatic Ewing sarcoma. Cancer Res 74(22): 6578-6588.

Boardman LA, Thibodeau SN, Schaid DJ, Lindor NM, McDonnell SK, Burgart LJ, Ahlquist DA, Podratz KC, Pittelkow M, Hartmann LC (1998) Increased risk for cancer in patients with the Peutz-Jeghers syndrome. Ann Intern Med 128(11): 896-899.

Boudeau J, Baas AF, Deak M, Morrice NA, Kieloch A, Schutkowski M, Prescott AR, Clevers HC, Alessi DR (2003) MO25alpha/beta interact with STRADalpha/beta enhancing their ability to bind, activate and localize LKB1 in the cytoplasm. EMBO J 22(19): 5102-5114.

Bouras T, Fu M, Sauve AA, Wang F, Quong AA, Perkins ND, Hay RT, Gu W, Pestell RG (2005) SIRT1 deacetylation and repression of p300 involves lysine residues 1020/1024 within the cell cycle regulatory domain 1. J Biol Chem 280(11): 10264-10276.

Calles A, Sholl LM, Rodig SJ, Pelton AK, Hornick JL, Butaney M, Lydon C, Dahlberg SE, Oxnard GR, Jackman DM, Janne PA (2015) Immunohistochemical loss of LKB1 is a biomarker for more aggressive biology in KRAS-mutant lung adenocarcinoma. Clin Cancer Res 21(12): 2851-2860. Chen X, Bahrami A, Pappo A, Easton J, Dalton J, Hedlund E, Ellison D, Shurtleff S, Wu G, Wei L, Parker M, Rusch M, Nagahawatte P, Wu J, 
Mao S, Boggs K, Mulder H, Yergeau D, Lu C, Ding L, Edmonson M, Qu C, Wang J, Li Y, Navid F, Daw NC, Mardis ER, Wilson RK, Downing JR, Zhang J, Dyer MA (2014) Recurrent somatic structural variations contribute to tumorigenesis in pediatric osteosarcoma. Cell Rep 7(1): 104-112.

Deng CX (2009) SIRT1, is it a tumor promoter or tumor suppressor? Int J Biol Sci 5(2): 147-152.

Fernanda Amary M, Ye H, Berisha F, Khatri B, Forbes G, Lehovsky K, Frezza AM, Behjati S, Tarpey P, Pillay N, Campbell PJ, Tirabosco R, Presneau N, Strauss SJ, Flanagan AM (2014) Fibroblastic growth factor receptor 1 amplification in osteosarcoma is associated with poor response to neo-adjuvant chemotherapy. Cancer Med 3(4): 980-987.

Gaude H, Aznar N, Delay A, Bres A, Buchet-Poyau K, Caillat C, Vigouroux A, Rogon C, Woods A, Vanacker JM, Hohfeld J, Perret C, Meyer P, Billaud M, Forcet C (2011) Molecular chaperone complexes with antagonizing activities regulate stability and activity of the tumor suppressor LKB1. Oncogene 31(12): 1582-1591.

Gentleman RC, Carey VJ, Bates DM, Bolstad B, Dettling M, Dudoit S, Ellis B, Gautier L, Ge Y, Gentry J, Hornik K, Hothorn T, Huber W, Iacus S, Irizarry R, Leisch F, Li C, Maechler M, Rossini AJ, Sawitzki G, Smith C, Smyth G, Tierney L, Yang JY, Zhang J (2004) Bioconductor: open software development for computational biology and bioinformatics. Genome Biol 5(10): R80.

Giardiello FM, Welsh SB, Hamilton SR, Offerhaus GJ, Gittelsohn AM, Booker SV, Krush AJ, Yardley JH, Luk GD (1987) Increased risk of cancer in the Peutz-Jeghers syndrome. N Engl J Med 316(24): 1511-1514.

Godlewski J, Nowicki MO, Bronisz A, Nuovo G, Palatini J, De Lay M, Van Brocklyn J, Ostrowski MC, Chiocca EA, Lawler SE (2010) MicroRNA-451 regulates LKB1/AMPK signaling and allows adaptation to metabolic stress in glioma cells. Mol Cell 37(5): 620-632.

Hardie DG, Alessi DR (2013) LKB1 and AMPK and the cancer-metabolism link - ten years after. BMC Biol 11: 36.

Hawley SA, Boudeau J, Reid JL, Mustard KJ, Udd L, Makela TP, Alessi DR, Hardie DG (2003) Complexes between the LKB1 tumor suppressor, STRAD alpha/beta and MO25 alpha/beta are upstream kinases in the AMP-activated protein kinase cascade. J Biol 2(4): 28.

Hori YS, Kuno A, Hosoda R, Horio Y (2013) Regulation of FOXOs and p53 by SIRT1 modulators under oxidative stress. PLoS ONE 8(9): e73875.

Ji H, Ramsey MR, Hayes DN, Fan C, McNamara K, Kozlowski P, Torrice C, Wu MC, Shimamura T, Perera SA, Liang MC, Cai D, Naumov GN, Bao L, Contreras CM, Li D, Chen L, Krishnamurthy J, Koivunen J, Chirieac LR, Padera RF, Bronson RT, Lindeman NI, Christiani DC, Lin X, Shapiro GI, Janne PA, Johnson BE, Meyerson M, Kwiatkowski DJ, Castrillon DH, Bardeesy N, Sharpless NE, Wong KK (2007) LKB1 modulates lung cancer differentiation and metastasis. Nature 448(7155): 807-810.

Knight JR, Milner J (2012) SIRT1, metabolism and cancer. Curr Opin Oncol 24(1): 68-75.

Kovac M, Blattmann C, Ribi S, Smida J, Mueller NS, Engert F, Castro-Giner F, Weischenfeldt J, Kovacova M, Krieg A, Andreou D, Tunn PU, Durr HR, Rechl H, Schaser KD, Melcher I, Burdach S, Kulozik A, Specht K, Heinimann K, Fulda S, Bielack S, Jundt G, Tomlinson I, Korbel JO, Nathrath M, Baumhoer D (2015) Exome sequencing of osteosarcoma reveals mutation signatures reminiscent of BRCA deficiency. Nat Commun 6: 8940

Lain S, Hollick JJ, Campbell J, Staples OD, Higgins M, Aoubala M, McCarthy A, Appleyard V, Murray KE, Baker L, Thompson A, Mathers J, Holland SJ, Stark MJ, Pass G, Woods J, Lane DP, Westwood NJ (2008) Discovery, in vivo activity, and mechanism of action of a small-molecule p53 activator. Cancer Cell 13(5): 454-463.

Lan F, Cacicedo JM, Ruderman N, Ido Y (2008) SIRT1 modulation of the acetylation status, cytosolic localization, and activity of LKB1. Possible role in AMP-activated protein kinase activation. J Biol Chem 283(41): 27628-27635.

Lao G, Liu P, Wu Q, Zhang W, Liu Y, Yang L, Ma C (2014) Mir-155 promotes cervical cancer cell proliferation through suppression of its target gene LKB1. Tumour Biol 35(12): 11933-11938.

Lee D, Goldberg AL (2013) SIRT1 protein, by blocking the activities of transcription factors FoxO1 and FoxO3, inhibits muscle atrophy and promotes muscle growth. J Biol Chem 288(42): 30515-30526.

Li J, Liu J, Li P, Mao X, Li W, Yang J, Liu P (2014) Loss of LKB1 disrupts breast epithelial cell polarity and promotes breast cancer metastasis and invasion. J Exp Clin Cancer Res 33: 70.

Li K, Luo J (2011) The role of SIRT1 in tumorigenesis. N Am J Med Sci 4(2): 104-106.

Lim CS (2007) Human SIRT1: a potential biomarker for tumorigenesis? Cell Biol Int 31(6): 636-637.
Lizcano JM, Goransson O, Toth R, Deak M, Morrice NA, Boudeau J, Hawley SA, Udd L, Makela TP, Hardie DG, Alessi DR (2004) LKB1 is a master kinase that activates 13 kinases of the AMPK subfamily, including MARK/PAR-1. EMBO J 23(4): 833-843.

Longhi A, Errani C, De Paolis M, Mercuri M, Bacci G (2006) Primary bone osteosarcoma in the pediatric age: state of the art. Cancer Treat Rev 32(6): 423-436.

Lorenz S, Baroy T, Sun J, Nome T, Vodak D, Bryne JC, Hakelien AM, Fernandez-Cuesta L, Mohlendick B, Rieder H, Szuhai K, Zaikova O, Ahlquist TC, Thomassen GO, Skotheim RI, Lothe RA, Tarpey PS, Campbell P, Flanagan A, Myklebost O, Meza-Zepeda LA (2016) Unscrambling the genomic chaos of osteosarcoma reveals extensive transcript fusion, recurrent rearrangements and frequent novel TP53 aberrations. Oncotarget 7(5): 5273-5288.

Momcilovic M, Shackelford DB (2015) Targeting LKB1 in cancer - exposing and exploiting vulnerabilities. Br J Cancer 113(4): 574-584.

Ottaviani G, Jaffe N (2009) The epidemiology of osteosarcoma. Cancer Treat Res 152: 3-13.

Ottaviano L, Schaefer KL, Gajewski M, Huckenbeck W, Baldus S, Rogel U, Mackintosh C, de Alava E, Myklebost O, Kresse SH, Meza-Zepeda LA, Serra M, Cleton-Jansen AM, Hogendoorn PC, Buerger H, Aigner T, Gabbert HE, Poremba C (2010) Molecular characterization of commonly used cell lines for bone tumor research: a trans-European EuroBoNet effort. Genes Chromosomes Cancer 49(1): 40-51.

Partanen JI, Tervonen TA, Myllynen M, Lind E, Imai M, Katajisto P, Dijkgraaf GJ, Kovanen PE, Makela TP, Werb Z, Klefstrom J (2012) Tumor suppressor function of liver kinase B1 (Lkb1) is linked to regulation of epithelial integrity. Proc Natl Acad Sci USA 109(7): E388-E397.

Patel K, Foretz M, Marion A, Campbell DG, Gourlay R, Boudaba N, Tournier E, Titchenell P, Peggie M, Deak M, Wan M, Kaestner KH, Goransson O, Viollet B, Gray NS, Birnbaum MJ, Sutherland C, Sakamoto K (2014) The LKB1-salt-inducible kinase pathway functions as a key gluconeogenic suppressor in the liver. Nat Commun 5: 4535.

Ritchie ME, Silver J, Oshlack A, Holmes M, Diyagama D, Holloway A, Smyth GK (2007) A comparison of background correction methods for two-colour microarrays. Bioinformatics 23(20): 2700-2707.

Robinson J, Nye E, Stamp G, Silver A (2008) Osteogenic tumours in Lkb1-deficient mice. Exp Mol Pathol 85(3): 223-226.

Sanchez-Cespedes M (2007) A role for LKB1 gene in human cancer beyond the Peutz-Jeghers syndrome. Oncogene 26(57): 7825-7832.

Sanchez-Cespedes M, Parrella P, Esteller M, Nomoto S, Trink B, Engles JM, Westra WH, Herman JG, Sidransky D (2002) Inactivation of LKB1/STK11 is a common event in adenocarcinomas of the lung. Cancer Res 62(13): 3659-3662.

Saunders LR, Sharma AD, Tawney J, Nakagawa M, Okita K, Yamanaka S, Willenbring H, Verdin E (2010) miRNAs regulate SIRT1 expression during mouse embryonic stem cell differentiation and in adult mouse tissues. Aging (Albany NY) 2(7): 415-431.

Shi L, Zhang B, Sun X, Lu S, Liu Z, Liu Y, Li H, Wang L, Wang X, Zhao C (2014) MiR-204 inhibits human NSCLC metastasis through suppression of NUAK1. Br J cancer 111(12): 2316-2327.

Shi Y, Huang J, Zhou J, Liu Y, Fu X, Li Y, Yin G, Wen J (2015) MicroRNA-204 inhibits proliferation, migration, invasion and epithelial-mesenchymal transition in osteosarcoma cells via targeting Sirtuin 1. Oncol Rep 34(1): 399-406.

Shorning BY, Clarke AR (2011) LKB1 loss of function studied in vivo. FEBS Lett 585(7): 958-966.

Sobottka SB, Haase M, Fitze G, Hahn M, Schackert HK, Schackert G (2000) Frequent loss of heterozygosity at the 19p13.3 locus without LKB1/STK11 mutations in human carcinoma metastases to the brain. J Neuro-oncol 49(3): 187-195

Strum JC, Johnson JH, Ward J, Xie H, Feild J, Hester A, Alford A, Waters KM (2009) MicroRNA 132 regulates nutritional stress-induced chemokine production through repression of SirT1. Mol Endocrinol 23(11): 1876-1884.

Sun Y, Yu X, Bai Q (2015) miR-204 inhibits invasion and epithelialmesenchymal transition by targeting FOXM1 in esophageal cancer. Int $J$ Clin Exp Pathol 8(10): 12775-12783.

Takeda S, Iwai A, Nakashima M, Fujikura D, Chiba S, Li HM, Uehara J, Kawaguchi S, Kaya M, Nagoya S, Wada T, Yuan J, Rayter S, Ashworth A, Reed JC, Yamashita T, Uede T, Miyazaki T (2007a) LKB1 is crucial for TRAIL-mediated apoptosis induction in osteosarcoma. Anticancer Res 27(2): 761-768. 
Takeda S, Iwai A, Nakashima M, Fujikura D, Chiba S, Li HM, Uehara J, Kawaguchi S, Kaya M, Nagoya S, Wada T, Yuan J, Rayter S, Ashworth A, Reed JC, Yamashita T, Uede T, Miyazaki T (2007b) LKB1 is crucial for TRAIL-mediated apoptosis induction in osteosarcoma. Anticancer Res 27(2): 761-768.

van Loosdregt J, Brunen D, Fleskens V, Pals CE, Lam EW, Coffer PJ (2011) Rapid temporal control of Foxp3 protein degradation by sirtuin-1. PLoS One 6(4): e19047.

Wang F, Chan CH, Chen K, Guan X, Lin HK, Tong Q (2011) Deacetylation of FOXO3 by SIRT1 or SIRT2 leads to Skp2-mediated FOXO3 ubiquitination and degradation. Oncogene 31(12): 1546-1557.

Wingo SN, Gallardo TD, Akbay EA, Liang MC, Contreras CM, Boren T, Shimamura T, Miller DS, Sharpless NE, Bardeesy N, Kwiatkowski DJ, Schorge JO, Wong KK, Castrillon DH (2009) Somatic LKB1 mutations promote cervical cancer progression. PLoS One 4(4): e5137.

Wu ZY, Wang SM, Chen ZH, Huv SX, Huang K, Huang BJ, Du JL, Huang CM, Peng L, Jian ZX, Zhao G (2015) MiR-204 regulates HMGA2 expression and inhibits cell proliferation in human thyroid cancer. Cancer Biomarkers 15(5): 535-542.

Yamakuchi M (2012) MicroRNA regulation of SIRT1. Front Physiol 3: 68.

Yamakuchi M, Ferlito M, Lowenstein CJ (2008) miR-34a repression of SIRT1 regulates apoptosis. Proc Natl Acad Sci USA 105(36): 13421-13426.

Yeung F, Hoberg JE, Ramsey CS, Keller MD, Jones DR, Frye RA, Mayo MW (2004) Modulation of NF-kappaB-dependent transcription and cell survival by the SIRT1 deacetylase. EMBO J 23(12): 2369-2380.

Yin Y, Zhang B, Wang W, Fei B, Quan C, Zhang J, Song M, Bian Z, Wang Q, Ni S, Hu Y, Mao Y, Zhou L, Wang Y, Yu J, Du X, Hua D, Huang Z (2014) miR-204-5p inhibits proliferation and invasion and enhances chemotherapeutic sensitivity of colorectal cancer cells by downregulating RAB22A. Clin Cancer Res 20(23): 6187-6199.

Ylikorkala A, Avizienyte E, Tomlinson IP, Tiainen M, Roth S, Loukola A, Hemminki A, Johansson M, Sistonen P, Markie D, Neale K, Phillips R, Zauber P, Twama T, Sampson J, Jarvinen H, Makela TP, Aaltonen LA (1999) Mutations and impaired function of LKB1 in familial and nonfamilial Peutz-Jeghers syndrome and a sporadic testicular cancer. Hum Mol Genet 8(1): 45-51.

Zhang L, Wang X, Chen P (2013) MiR-204 down regulates SIRT1 and reverts SIRT1-induced epithelial-mesenchymal transition, anoikis resistance and invasion in gastric cancer cells. BMC Cancer 13: 290.

Zheng Z, Chen H, Li J, Li T, Zheng B, Zheng Y, Jin H, He Y, Gu Q, Xu X (2012) Sirtuin 1-mediated cellular metabolic memory of high glucose via the LKB1/AMPK/ROS pathway and therapeutic effects of metformin. Diabetes 61(1): 217-228.

Zhong D, Guo L, de Aguirre I, Liu X, Lamb N, Sun SY, Gal AA, Vertino PM, Zhou W (2006) LKB1 mutation in large cell carcinoma of the lung. Lung Cancer 53(3): 285-294.

Zu Y, Liu L, Lee MY, Xu C, Liang Y, Man RY, Vanhoutte PM, Wang Y (2010) SIRT1 promotes proliferation and prevents senescence through targeting LKB1 in primary porcine aortic endothelial cells. Circ Res 106(8): 1384-1393.

This work is published under the standard license to publish agreement. After 12 months the work will become freely available and the license terms will switch to a Creative Commons AttributionNonCommercial-Share Alike 4.0 Unported License.

Supplementary Information accompanies this paper on British Journal of Cancer website (http://www.nature.com/bjc) 